\title{
Molecular characterization of a deletion/duplication rearrangement in tfd genes from Ralstonia eutropha JMP134(pJP4) that improves growth on 3-chlorobenzoic acid but abolishes growth on 2,4-dichlorophenoxyacetic acid
}

\author{
Pascale Clément, ${ }^{1}$ Dietmar H. Pieper ${ }^{2}$ and Bernardo González ${ }^{1}$
}

Author for correspondence: Bernardo González. Tel: +56 26862845. Fax: +5622225515. e-mail: bgonzale@genes.bio.puc.cl

1 Laboratorio de Microbiología, Departamento de Genética Molecular y Microbiología, Facultad de Ciencias Biológicas, Pontificia Universidad Católica de Chile, Alameda 340, Casilla 114-D, Santiago, Chile

2 Division of Microbiology, National Research Centre for Biotechnology - GBF, Braunschweig, Germany

\begin{abstract}
Ralstonia eutropha JMP134(pJP4) is able to grow on minimal media containing the pollutants 3-chlorobenzoate (3-CB) or 2,4-dichlorophenoxyacetate (2,4-D). $t f d$ genes from the $88 \mathrm{~kb}$ plasmid pJP4 encode enzymes involved in the degradation of these compounds. During growth of strain JMP134 in liquid medium containing 3-CB, a derivative strain harbouring a $\sim 95 \mathrm{~kb}$ plasmid was isolated. This derivative, designated JMP134(pJP4-F3), had an improved ability to grow on 3-CB, but had lost the ability to grow on 2,4-D. Sequence analysis of pJP4-F3 indicated that the plasmid had undergone a deletion of $\sim 16 \mathrm{~kb}$, which included the $t f d A-t f d S$ intergenic region, spanning the $t f d A$ gene to a previously unreported IS1071 element. The loss of the $t \mathrm{fdA}$ gene explains the failure of the derivative to grow on 2,4-D. A $\sim 23 \mathrm{~kb}$ duplication of the region spanning $t f d R-t f d D_{11} C_{11} E_{11} F_{11}-t f d B_{11}-t f d K$-ISJP4-tfdT-tfdC $C_{1} D_{1} E_{1} F_{1}-t f d B_{11}$ giving rise to a 51-kb-long inverted repeat, was also observed. The increase in gene copy number for the $t f d C D(D C) E F$ gene cluster may provide an explanation for the derivative strain's improved growth on 3-CB. These observations are additional examples of the metabolic plasticity of $R$. eutropha JMP134, one of the more versatile pollutant-degrading bacteria.
\end{abstract}

Keywords: chloroaromatics, catabolic plasmid, IS1071 insertion sequence, chlorocatechol pathway

\section{INTRODUCTION}

Bacteria play a fundamental role in the degradation of chloro-organic pollutants. Ralstonia eutropha JMP134(pJP4) degrades several chloroaromatic compounds through chromosomal (Clément et al., 1995) or plasmid (pJP4)-encoded functions (Don \& Pemberton, 1981; Pieper et al., 1988). Plasmid pJP4 is an $88 \mathrm{~kb}$, selftransmissible, broad-host-range, catabolic plasmid belonging to the $\operatorname{IncP} \beta$ incompatibility group (Don \& Pemberton, 1981; Smith \& Thomas, 1987). pJP4 con-

Abbreviations: 3-CB, 3-chlorobenzoate; 2,4-D, 2,4-dichlorophenoxyacetate.

The GenBank accession numbers for the $3115 \mathrm{nt}$ BamHI-F and $2833 \mathrm{nt}$ ECoRI-F fragments of pJP4 and the $4037 \mathrm{nt}$ EcoRI-E' fragment of pJP4-F3 are AF225972, AF225973 and AF225974, respectively. tains genes $(t f d)$ encoding enzymes involved in the catabolism of 2,4-dichlorophenoxyacetate $(2,4-\mathrm{D})$ and 3 -chlorobenzoate (3-CB), which have been intensively studied. The $t f d$ genes are located in a $20-\mathrm{kb}$-long region surrounded by a conserved IncP $\beta$ plasmid backbone (Burlage et al., 1990). The organization of the $t f d$ genes is complex (Fig. 1). The $t f d A$ gene encodes a dioxygenase that converts 2,4-D to 2,4-dichlorophenol (Fukumori \& Hausinger, 1993). The $t f d B$ gene encodes a 2,4dichlorophenol monooxygenase that hydroxylates 2,4dichlorophenol to 3,5-dichlorocatechol (Perkins et al., 1990). Two different gene clusters, $t f d C_{\mathrm{I}} D_{\mathrm{I}} E_{\mathrm{I}} F_{\mathrm{I}}$ and $t f d D_{\mathrm{II}} C_{\mathrm{II}} E_{\mathrm{II}} F_{\mathrm{II}}$ (Fig. 1), encode enzymes for the catabolism of chlorocatechols to 3-oxoadipate. The enzymes from both modules are active during degradation of 2,4-D (Leveau et al., 1999; Laemmli et al., 2000) and 3-CB (Pérez-Pantoja et al., 2000). Two 


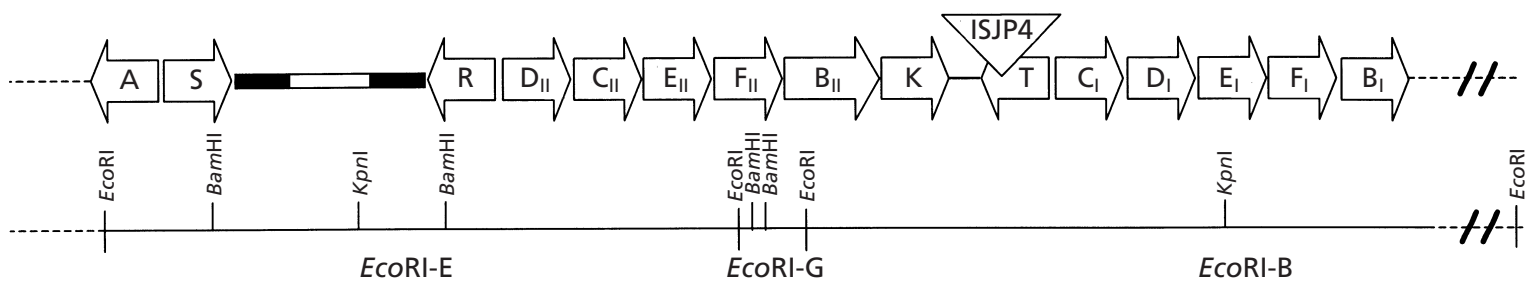

Fig. 1. Schematic diagram of the $t f d$ catabolic region of pJP4. The approximate position of $t f d$ genes, the ISJP4 insertion sequence, and the EcoRI, HindIII, BamHI and Kpnl restriction sites are indicated. Black and white bars correspond to previously sequenced and unsequenced regions of the BamHI internal part of the EcoRI-E fragment, respectively. Not to scale.

identical regulatory genes, $t f d R$ and $t f d S$, have also been described (Matrubutham \& Harker, 1994).

During the course of a study of the role of $t f d$ genes in the degradation of 3-CB (Pérez-Pantoja et al., 2000), a derivative of strain JMP134 was isolated that exhibited improved growth on 3-CB but failed to grow on 2,4-D. This derivative (JMP134-F3) harbours a larger $\sim 95 \mathrm{~kb}$ form of pJP4, designated pJP4-F3, the molecular characterization of which is reported here.

\section{METHODS}

Bacterial strains and growth conditions. $R$. eutropha JMP134(pJP4) was obtained from the Deutsche Sammlung von Mikroorganismen und Zellkulturen GmbH (Braunschweig, Germany) and was routinely grown on solid minimal medium containing $2 \mathrm{mM}$ 2,4-D or 3-CB (Kröckel \& Focht, 1987). Escherichia coli XL-1 Blue (Bullock et al., 1987) was used for cloning and sequencing. Cultures of R. eutropha and its derivatives were grown at $30^{\circ} \mathrm{C}$. E. coli cultures were incubated at $37^{\circ} \mathrm{C}$. Bacterial matings were performed on Luria-Bertani (LB) plates as described by Clément et al. (2000). Growth rates were calculated from the slopes of the corresponding growth $\left(\mathrm{OD}_{660}\right.$ versus time) curves.

DNA manipulation. Screening for plasmid pJP4 was carried out by the procedure described by Kado \& Liu (1981). Plasmid DNA was visualized after electrophoresis on agarose gel $(0.8 \%, \mathrm{w} / \mathrm{v}$, in electrophoresis running buffer containing $40 \mathrm{mM}$ Tris/acetate and $1 \mathrm{mM}$ EDTA, pH 8.0) for $5 \mathrm{~h}$ at a constant voltage of $70 \mathrm{~V}$. pJP4 DNA suitable for restriction and Southern analysis was prepared from E. coli XL-1 Blue derivatives obtained after conjugative transfer of the wild-type plasmid or its derivative, pJP4-F3, from R. eutropha JMP134 (Clément et al., 2000), using the Spin Miniprep Kit (Qiagen). Total cellular DNA preparations were made using the Wizard genomic DNA purification kit (Promega). Restriction, ligation and dephosphorylation reactions and the electroporation of DNA were performed by standard procedures (Ausubel et al., 1992).

Southern blots of pJP4 DNA fragments (obtained after digestion with HindIII, EcoRI or BamHI and separation on a $0.7 \%$ agarose gel) were made using Hybond $\mathrm{N}+$ membranes (Amersham Pharmacia Biotech). Probes were labelled using the BioNick labelling system and hybridization was detected with the PhotoGene nucleic acid detection system (GibcoBRL), as recommended by the supplier. An 801 bp StyI fragment of the $t f d A$ gene was used as a probe (Holben et al.,
1992). The remaining probes were prepared from the PCR amplification products cloned in pGem-T Easy (Promega). The IS1071-AB and IS1071-AC probes were obtained with primer pairs IS1071-A (GGGGTCTCCTCGTTTTCAGTGCAA) and IS1071-B (CTTTGAGATATAAAGCTTGCAGCT), and IS1071-A and IS1071-C (GATCCAGAAAGCTGCCAGTTGAAG), respectively (Xia et al., 1998). Detection of the intergenic region between $t f d A$ and $t f d S$ was carried out by PCR amplification using primer pairs PR33 (GCCGCGCTATTTCTGTCCTTTCCCG, base pairs 984-1008; GenBank accession no. S80112) and RC3 (TCGACCCCTGCGGCG, base pairs 783-797; GenBank accession no. M16730). The conditions for the PCR were as follows: $95^{\circ} \mathrm{C}$ for $5 \mathrm{~min}, 52^{\circ} \mathrm{C}$ for $1.5 \mathrm{~min}$ and $72{ }^{\circ} \mathrm{C}$ for $3.5 \mathrm{~min} ; 32$ cycles of $95^{\circ} \mathrm{C}$ for $1.5 \mathrm{~min}, 55^{\circ} \mathrm{C}$ for $1 \mathrm{~min}$ and $72^{\circ} \mathrm{C}$ for $3 \mathrm{~min}$; and finally $72{ }^{\circ} \mathrm{C}$ for $10 \mathrm{~min}$. The final concentrations were $0.5 \mathrm{pM}$ for the primers, $250 \mu \mathrm{M}$ for the dNTPs, $2 \mathrm{mM} \mathrm{MgCl}_{2}$ and $0.5 \mathrm{U}$ Taq polymerase per $10 \mu \mathrm{l}$ reaction. PCR amplification for the generation of IS1071 probes was performed as described by Xia et al. (1998). The reactions were carried out in a MiniCycler (MJ Research).

Sequence analysis. Subcloning of fragments for sequencing was carried out in pBlueScript II SK $(+/-)$. Nucleotide sequencing of both DNA strands was carried out using a PRISM sequencing kit (Perkin-Elmer) with double-stranded DNA templates in the presence of $5 \%$ DMSO. Samples containing fluorescence-labelled dideoxynucleotide terminators were processed on a 373 stretch automated sequencer (Applied Biosystems). Sequences were compiled and analysed using DNASTAR software (DNAstar). The computational resource of the National Centre of Biotechnology Information was used through the BLASTX software facilities.

Enzyme assays. R. eutropha JMP134 and its derivatives were grown for $24 \mathrm{~h}$ on liquid minimal medium containing $2 \mathrm{mM}$ 2,4-D or 3-CB. A $100 \mathrm{ml}$ aliquot of each culture was harvested at the end of the exponential growth phase by centrifugation for $15 \mathrm{~min}$ at 7000 r.p.m. in a Beckman J2-21 centrifuge, washed twice in minimal medium and resuspended in $5 \mathrm{ml}$ $50 \mathrm{mM}$ Tris/acetate, $\mathrm{pH} 7 \cdot 5$. Cells were disrupted by sonication (Sonics \& Materials) four times for 30 s at $90 \%$ of the maximum output, and the soluble protein fraction was obtained after $1 \mathrm{~h}$ centrifugation at $130000 \mathrm{~g}$ in a Beckman L80 ultracentrifuge. Cell extracts $\left(0 \cdot 1-5 \cdot 0 \mathrm{mg}\right.$ protein $\left.\mathrm{ml}^{-1}\right)$ were assayed without further purification. Chlorocatechol 1,2dioxygenase activity was assayed and quantified as described elsewhere (Pérez-Pantoja et al., 2000). Protein determinations were performed as described by Bradford (1976).

Nucleotide sequence accession numbers. The GenBank accession numbers for the $3115 \mathrm{nt}$ BamHI-F and $2833 \mathrm{nt}$ 
EcoRI-F fragments of pJP4 and the 4037 nt EcoRI-E' fragment of pJP4-F3 are AF225972, AF225973 and AF225974, respectively.

\section{RESULTS}

\section{Derivatives of $R$. eutropha JMP134 growing on 3-CB have an enlarged pJP4 plasmid}

$R$. eutropha JMP134 is routinely transferred on solid medium containing 2,4-D or 3-CB without there being any change in the electrophoretic mobility of the pJP4 plasmid. However, when strain JMP134 was grown in liquid minimal medium containing $3 \mathrm{mM} 3-\mathrm{CB}$, an enlarged $(\sim 95 \mathrm{~kb})$ pJP4 form was detected by gel electrophoresis (data not shown). To study the frequency of this phenomenon, liquid cultures of strain JMP134 in minimal medium containing 3-CB or 2,4-D were subcultured to the same fresh medium every $2 \mathrm{~d}$, then plated on LB agar media to isolate colonies. After three subcultures in $3 \mathrm{mM} 3-\mathrm{CB}, 30 \%$ of colonies (of 50 analysed each transfer) showed the presence of the enlarged plasmid. After five subcultures, more than $90 \%$ of colonies possessed the enlarged plasmid. When strain JMP134 was subcultured to liquid medium containing $2 \mathrm{mM} 3-\mathrm{CB}, 5$ and $25 \%$ of colonies showed the enlarged plasmid after three and five subcultures, respectively. In contrast, no colonies harbouring the enlarged pJP4 were detected after eight subcultures to liquid medium containing $3 \mathrm{mM}$ 2,4-D. Interestingly, all colonies possessing the enlarged plasmid were unable to grow on 2,4-D, either in liquid medium containing 1-3 mM 2,4-D or on solid medium containing $2 \mathrm{mM}$ 2,4-D. All such colonies gave no PCR product when tested for the presence of an IS1071 sequence (see below), using primer pair IS1071A/C. One of the colonies harbouring the enlarged $\mathrm{pJP} 4$ form was designated JMP134-F3 and was selected for further analysis. All cells harbouring the enlarged pJP4 plasmid were unable to grow on 2,4-D medium, but grew two times faster than the wild-type on liquid cultures with $3 \mathrm{mM}$ 3-CB, and showed higher chlorocatechol 1,2dioxygenase (TfdC) specific activity in crude extracts (Table 1).

\section{Restriction profiles: comparison of the wild-type and enlarged pJP4 plasmids}

EcoRI, HindIII and BamHI restriction profiles were determined for plasmid JP4-F3 from strain JMP134-F3, and were observed to be different from those for wildtype pJP4, and strikingly similar to those reported previously for plasmid pYG2, another pJP4 derivative (Ghosal et al., 1985). EcoRI fragments C, E, F, H and I, as well as the HindIII-B, -D, -E and -H and BamHI-B fragments of pJP4, were absent in pJP4-F3 (see Fig. 2a for orientation). Some new fragments were clearly visible in pJP4-F3, i.e. EcoRI-C', EcoRI-E', HindIII-B' and HindIII-D' (see Fig. 2b for orientation). Ghosal \& You (1988) reported that the EcoRI-C band of pYG2 corresponded to two fragments, the wild-type EcoRI-D $(10 \cdot 2 \mathrm{~kb})$, and a distinct $10 \cdot 2 \mathrm{~kb}$ EcoRI fragment, which hybridized with the wild-type EcoRI-E fragment (see Fig. $2 \mathrm{a}$, b for orientation). Similarly, the $10.2 \mathrm{~kb}$ band of EcoRI-digested pJP4-F3 DNA was shown to consist of two fragments. Cloning of the $10 \cdot 2 \mathrm{~kb}$ DNA band into pUC19 resulted in two kinds of clones. One of these contained an insert without a KpnI restriction site, as the wild-type EcoRI-D fragment. The other insert, designated EcoRI-C' in Fig. 2b, exhibited one KpnI restriction site corresponding to that present in the wild-type EcoRI-E fragment (Fig. 1).

\section{Comparison of the sequences of EcoRI fragments from strains JMP134 and JMP134-F3, containing the $t f d R / S$ regulatory region}

The EcoRI-C' fragment of pJP4-F3 should contain the regulatory genes $t f d R$ and $t f d S$ of the EcoRI-E fragment of pJP4 (Fig. 1). As strain JMP134-F3 exhibited different growth characteristics and chlorocatechol 1,2-dioxygenase activity with respect to wild-type strain JMP134 (Table 1), a more detailed study of the wild-type and the pJP4-derivative fragments containing the regulatory genes was carried out. The $8.3 \mathrm{~kb}$ EcoRI-E fragment from $\mathrm{pJP} 4$ and the $10 \cdot 2 \mathrm{~kb} E c o R I-C^{\prime}$ fragment from pJP4-F3 were cloned in pUC19, yielding plasmids pE83 and pEF102, respectively (Fig. 2a, b). Since a significant part of the wild-type EcoRI-E fragment has already been

Table 1. Relative growth rate and chlorocatechol 1,2-dioxygenase (CC 1,2-DO) specific activity for $R$. eutropha strains JMP134 and JMP134-F3 growing on 2,4-D or 3-CB

\begin{tabular}{|lccc|}
\hline Strain & Growth substrate & $\begin{array}{c}\text { Relative growth } \\
\text { rate }\end{array}$ & $\begin{array}{c}\text { CC 1,2-DO specific } \\
\text { activity }\left(\mathbf{U ~ m g}^{-1}\right) \dagger\end{array}$ \\
\hline JMP134 & 2,4-D & $1 \cdot 0$ & $0 \cdot 63 \pm 0 \cdot 05$ \\
JMP134 & 3-CB & $1 \cdot 0$ & $0 \cdot 38 \pm 0 \cdot 09$ \\
JMP134-F3 & 2,4-D & $0 \cdot 0$ & NA \\
JMP134-F3 & 3-CB & $2 \cdot 0$ & $1 \cdot 72 \pm 0 \cdot 26$ \\
\hline
\end{tabular}

*Growth was tested for up to $5 \mathrm{~d}$. Values are means of two independent experiments. Growth rates for strain JMP134 in 2,4-D and 3-CB were $0 \cdot 24 \mathrm{~h}^{-1}$ and $0 \cdot 31 \mathrm{~h}^{-1}$, respectively.

† Values are means of three independent experiments carried out with crude extracts from cells grown on 2,4-D or 3-CB as sole carbon and energy source. NA, Not applicable. 
(a)

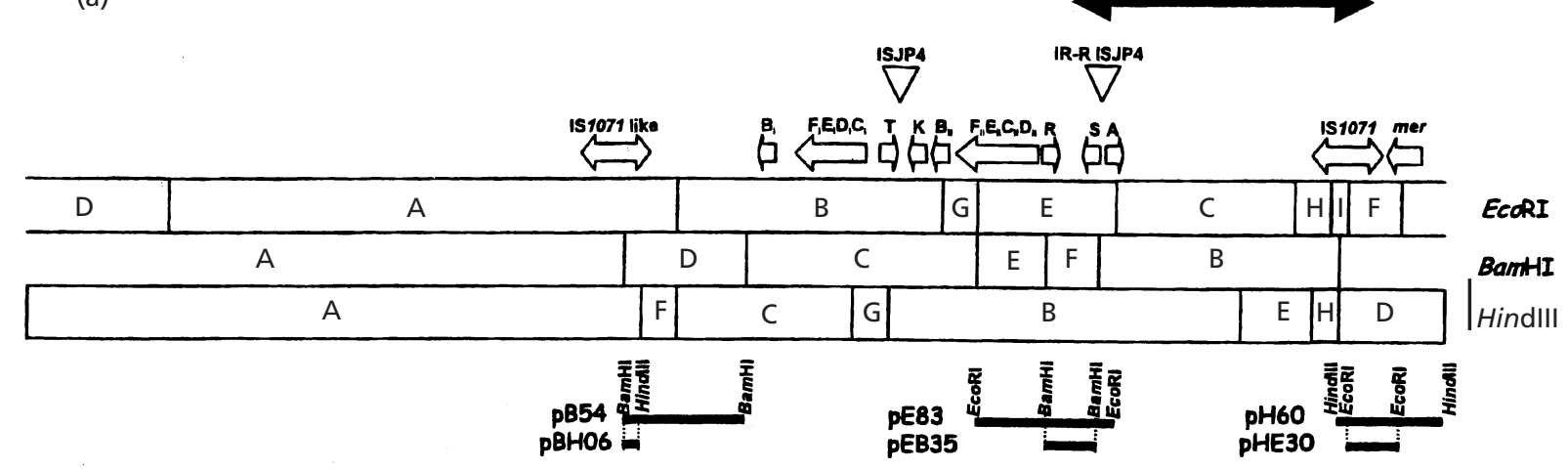

(b)

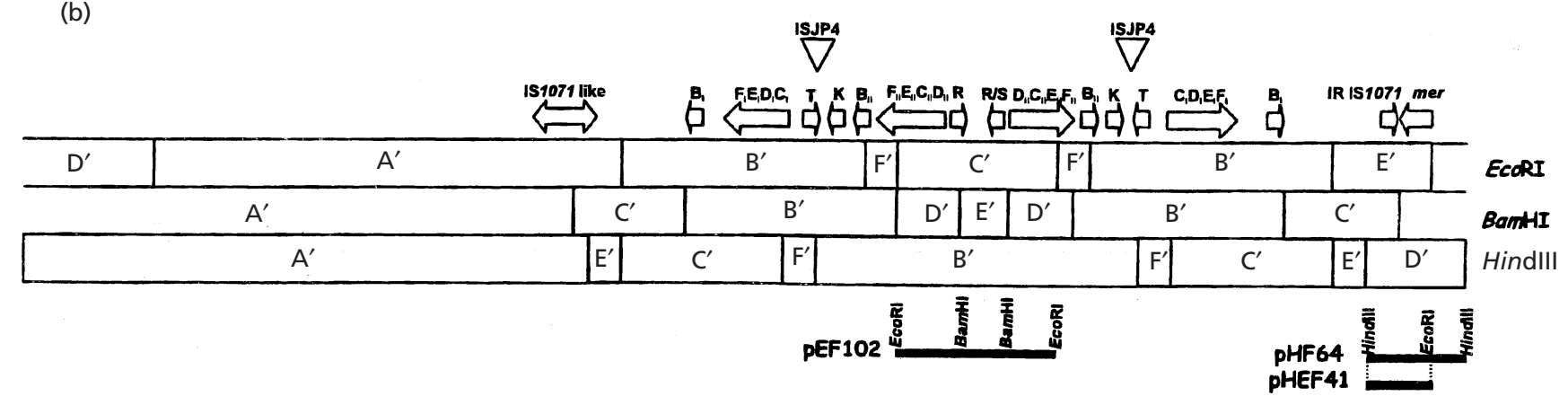

(c)

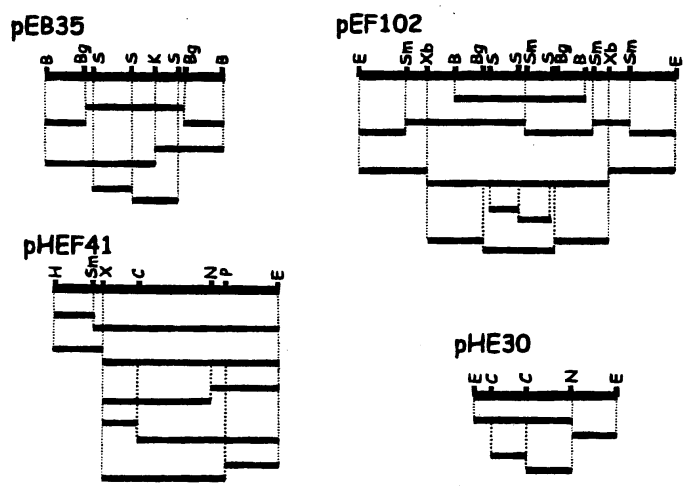

(d)

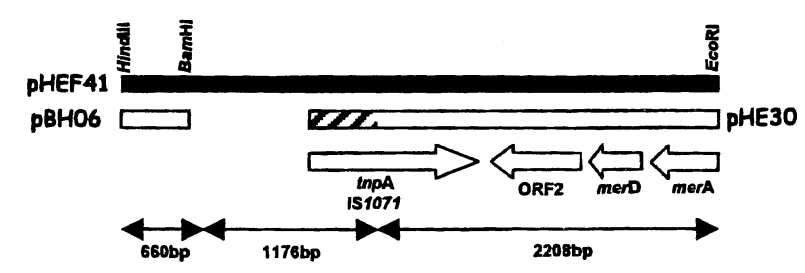

Fig. 2. (a, b) Comparison of the EcoRI, BamHI and HindIII physical and genetic maps (not to scale) of pJP4 (a) and pJP4-F3 (b), based on published maps (Don \& Pemberton, 1985; Ghosal et al., 1985) and this work. The approximate positions of the $t f d$ and mer genes and the ISJP4, IR-R-ISJP4, IS1071 and IS1071-like elements are shown. The double-headed, solid arrow on the PJP4 map corresponds to sequences that are not present in pJP4-F3. The double-headed, solid arrow on the pJP4-F3 map corresponds to duplicated sequences. The relevant clones used in this study from the wild-type (a) or the rearranged pJP4 derivative (b) are shown as black bars. (c) Strategy used to sequence relevant subclones from pEB35, pEF102, pHEF41 and pHE30. Abbreviations: B, BamHI; E, EcoRI; H, HindIII; Bg, Bg/ll; S, Sacl; K, Kpnl; C, Clal; N, Notl; Sm, Smal; X, Xhol; Xb, Xbal; P, Pstl. (d) Enlargement of part of the Hindlll-D' fragment of pJP4-F3 containing the junction region. The black and white bars correspond to pJP4-F3 and pJP4 sequenced DNA, respectively. The hatched region in pHE30 corresponds to the region where the homology to pHFE41 is lost. The positions of the ORFs are depicted.

sequenced (Leveau \& van der Meer, 1996; You \& Ghosal, 1995), only the BamHI-F internal fragment of the EcoRI-E fragment, containing sequences not yet reported (Fig. 1), was analysed. The BamHI-F DNA fragment was cloned into pBlueScript, giving pEB35 (Fig. 2a), and a number of subclones for sequencing were 
obtained from that plasmid, as well as from plasmid pEF102 (Fig. 2c). The sequence of the BamHI insert in pEB35 showed the presence of part of the two inverted repeats containing the $t f d S$ and $t f d R$ genes, and a 1277 bp-long non-repeated sequence (GenBank accession no. AF225972). When the sequence of the EcoRI-C' DNA in pEF102 was compared with the wild-type EcoRI-E sequence, the Bam HI-F and BamHI-E' fragments were found to be identical. Surprisingly, the two sequences flanking BamHI-E' in pEF102 (BamHI-D' in Fig. 2b) were found to be identical but inverted, and also identical to DNA corresponding to BamHI-E in pE83 (Fig. 2a). This indicates that a mirror copy of the $t f d R-t f d D_{\mathrm{II}}$ region in $\mathrm{pJP} 4-\mathrm{F} 3$ had replaced the $t f d A-$ $t f d S$ region of the wild-type, producing a large inverted repeat. Further details of this duplication are given below. This information, along with the data from the restriction profile of pJP4-F3 (Fig. 2b), indicates that the deletion includes the wild-type fragments EcoRI-C, -H and -I, and parts of the fragments EcoRI-E and -F (double-headed solid arrow in Fig. 2a). The absence of the $t f d A-t f d S$ intergenic region in pJP4-F3 was further confirmed by the fact that the expected $1.1 \mathrm{~kb}$ PCR product obtained using primer pair PR 33 and RC 3 could be amplified only from pE83 and not from pEF102, and, correspondingly, from pJP4 but not from pJP4-F3. Southern analysis of the total DNA of strain JMP134$\mathrm{F}$, using $t f d A$ as the probe, showed that the sequence of this gene was not present. The absence of $t f d A$ in strain JMP134-F3 explains its failure to grow on 2,4-D (Table 1).

\section{Determination of the ends of the large inverted repeat in PJP4-F3}

As mentioned above, a deletion starting in the pJP4 fragment EcoRI-E, spanning fragments EcoRI-C, -H and $-\mathrm{I}$, and ending in the fragment EcoRI-F, occurred to yield pJP4-F3 (for orientation, see double-headed solid arrow in Fig. 2a). In addition, the observation that the EcoRI insert in pEF102 is an inverted repeat shows that a duplication spanning at least the $t f d R, t f d D_{\mathrm{II}}$ and $t f d C_{\text {II }}$ genes had occurred. This duplication may be significantly longer and may exceed the length of the deletion since pJP4-F3 is larger than the parent pJP4 plasmid. Thus, the duplication may possibly span both the $t f d C_{\mathrm{I}} D_{\mathrm{I}} E_{\mathrm{I}} F_{\mathrm{I}}$ module and the $t f d D_{\mathrm{II}} C_{\mathrm{II}} E_{\mathrm{II}} F_{\mathrm{II}}$ module (see double-headed solid arrow in Fig. 2b). Besides EcoRI-C', the fragment in which the duplication/ deletion starts, the only other new EcoRI fragment visible after pJP4-F3 digestion is EcoRI-E'. Therefore, it may be assumed that the second duplication/deletion junction lies within this fragment (Fig. 2b). Correspondingly, this junction should also lie within the HindIII-D' fragment of pJP4-F3 (Fig. 2b). The HindIII$\mathrm{D}^{\prime}$ fragment from pJP4-F3 was cloned in pBlueScript to give pHF64 (Fig. 2b), and was used as a probe against pJP4 and pJP4-F3 plasmid DNA digested with HindIII, EcoRI and BamHI. Wild-type pJP4 EcoRI-F and HindIII-D fragments, containing sequences that should be partially deleted in pJP4-F3, hybridized with the probe, suggesting that HindIII-D' contains the deletion/ duplication end-point (Fig. 2b). Hybridization was also observed with the wild-type BamHI-A, BamHI-D and EcoRI-A fragments, indicating that sequences within fragments EcoRI-F and EcoRI-A have some homology and might flank the large inverted repeat (Fig. 2a). Thus, it can be assumed that the duplication occurring in $\mathrm{pJP4}$ F3 encompasses part of the wild-type EcoRI-E, all of the EcoRI-G and -B fragments and part of the -A fragments, and that the duplication end localized in the EcoRI-A fragment joins the deletion end localized in the EcoRI-F fragment, forming the new HindIII-D' and EcoRI-E' fragments (Fig. 2a, b).

To verify this assumption, the HindIII-D fragment of pJP4 was cloned into pBlueScript, to give pH60 (Fig. 2a), and the HindIII-D' fragment of pJP4-F3 was cloned to produce pHF64 (Fig. 2b). EcoRI subclones from pH60 and pHF64 were prepared in pBlueScript to give pHE30 and pHEF41 (Fig. 2a, b). The BamHI-D fragment from the pJP4 plasmid with homology to the HindIII-D' fragment (Fig. 2b) was also cloned in pBlueScript to give pB54 (Fig. 2a). This plasmid was digested with HindIII and the smallest fragment $(0.6 \mathrm{~kb})$ was also cloned in pBlueScript to give pBH06 (Fig. 2a). Cloned fragments in plasmids pHE30, pHEF41 and pBH06 were sequenced (GenBank accession nos AF225973 and AF225974 for the first two clones, respectively). Subclones used for the sequencing of pHEF41 and pHE30 are shown in Fig. 2(c). As is depicted in Fig. 2(d), 2208 bp from the EcoRI-end of pHEF41 (part of the HindIII-D' fragment) are identical to those of pHE30 (part of the HindIII-D fragment); $660 \mathrm{bp}$ at the HindIII-end of pHEF41 are identical in sequence to pBH06 (part of the BamHI-D fragment). The $\sim 1.2 \mathrm{~kb}$ of pHEF41 between these regions of homology does not match with either of these sequences, and should correspond to the Bam HI-Afragment end, next to the BamHI-D fragment in the wild-type (see Fig. 2a).

A search for sequence homologies in pHE30 and pHEF41 was conducted. A BLASTX analysis of the sequence of pHE30 (Fig. 2d) yielded $99 \%$ identity for merA (mercury reductase) of Tn501 (Brown et al., 1983), $99 \%$ identity with merD from Pseudomonas stutzeri (Reniero et al., 1998), 99\% identity with ORF2 of the mercury-resistance transposon from $P$. stutzeri (Reniero et al., 1998), and $100 \%$ identity with tnpA of IS1071 in Tn5271 (Nakatsu et al., 1991). Since IS1071 has been localized in catabolic transposons and has been involved in DNA rearrangements, the presence of IS1071 sequences in pJP4 and pJP4-F3 was further studied by Southern analysis. Probes IS1071-AB and IS1071-AC, which correspond to the left and right halves of IS1071, respectively (Xia et al., 1998), gave the same hybridization pattern. The EcoRI-A, -F, -H and -I fragments from wild-type pJP4, and the EcoRI-A' and $-E^{\prime}$ fragments from pJP4-F3 hybridized with the IS1071 probe. Fragments BamHI-A and -B, HindIII-A, -D, -E and -H from pJP4, and BamHI-A', BamHI-C', HindIII$\mathrm{A}^{\prime}$ and $-\mathrm{D}^{\prime}$ from pJP4-F3 also hybridized (see maps in Fig. $2 \mathrm{a}, \mathrm{b}$ for orientation). This evidence, along with 
sequence data, strongly suggests that there is at least one copy of an IS1071 in pJP4. As the EcoRI-A, HindIII-A and BamHI-A fragments of pJP4 also hybridized with both IS1071 probes, it can be suggested that an IS1071like element, or part of IS1071, is also present.

During the rearrangement, the part of the IS1071 sequence (containing two EcoRI recognition sites) that corresponds to fragments EcoRI-H, -I and -F was deleted (Fig. 2a). As a consequence, primer IS1071-AC could not anneal; this meant that it was no longer possible to amplify this sequence with primers IS1071A/C. The difference between the wild-type and rearranged plasmids was used to screen isolated colonies, and to quantify the rearrangement frequency (see above).

The data indicate that pJP4-F3 is the result of a duplication event involving a $\sim 23 \mathrm{~kb}$ section that starts in the $t f d S$ gene or the $t f d A-t f d S$ intergenic region belonging to the $t f d R / t f d S$ small inverted repeat, spans both the $t f d C_{\mathrm{I}} D_{\mathrm{I}} E_{\mathrm{I}} F_{\mathrm{I}}$ module and the $t f d D_{\mathrm{II}} C_{\mathrm{II}} E_{\mathrm{II}} F_{\mathrm{II}}$ module, and ends $1176 \mathrm{bp}$ into the Bam HI-A fragment. Plasmid pJP4 also underwent a deletion that starts in the $t f d S$ gene or the $t f d A-t f d S$ intergenic region and ends $637 \mathrm{bp}$ (corresponding to the hatched region of pHE30 shown in Fig. 2d) into the wild-type EcoRI-F fragment, leaving only the right portion of the IS1071. The absence of $t f d A$ explains the inability of strain JMP134-F3 to grow on 2,4-D. On the other hand, the duplication that forms a 51-kb-long inverted repeat containing two copies of both $t f d C D(D C) E F$ gene clusters is responsible for the increased TfdC activity, and supports the improved growth of this strain on 3-CB.

\section{DISCUSSION}

In this work, we have reported a deletion/duplication rearrangement of $\mathrm{pJP} 4$ produced after subculture of $R$. eutropha JMP134 in liquid medium containing 3-CB. The restriction enzyme profile and the presence of a very long inverted repeat $(\sim 51 \mathrm{~kb}$, including the loop) in the enlarged pJP4 are very similar (if not identical) to that previously reported by Ghosal et al. (1985). In that case, however, the enlarged pJP4 form was obtained after conjugative transfer of $\mathrm{pJP} 4$ from $R$. eutropha to a Pseudomonas putida, followed by selection for growth on 3-CB. Although strain JMP134 is capable of growth both on solid and in liquid cultures containing 3-CB without rearrangements of plasmid pJP4, repeated subculturing in liquid medium readily selects for bacteria containing the rearranged plasmid. These observations suggest that the driving force for this rearrangement was the selective pressure for efficient growth on 3-CB. Accordingly, one of the outcomes of this rearrangement is the duplication of most of the region containing the $t f d C D(D C) E F$ gene clusters. It has been shown recently that a $t f d$ gene dosage effect is important for efficient growth on 3-CB of R. eutropha JMP134 derivatives (Pérez-Pantoja et al., 2000). Additional examples of the effect of gene dosage on growth on chloroaromatics by the modified ortho ring
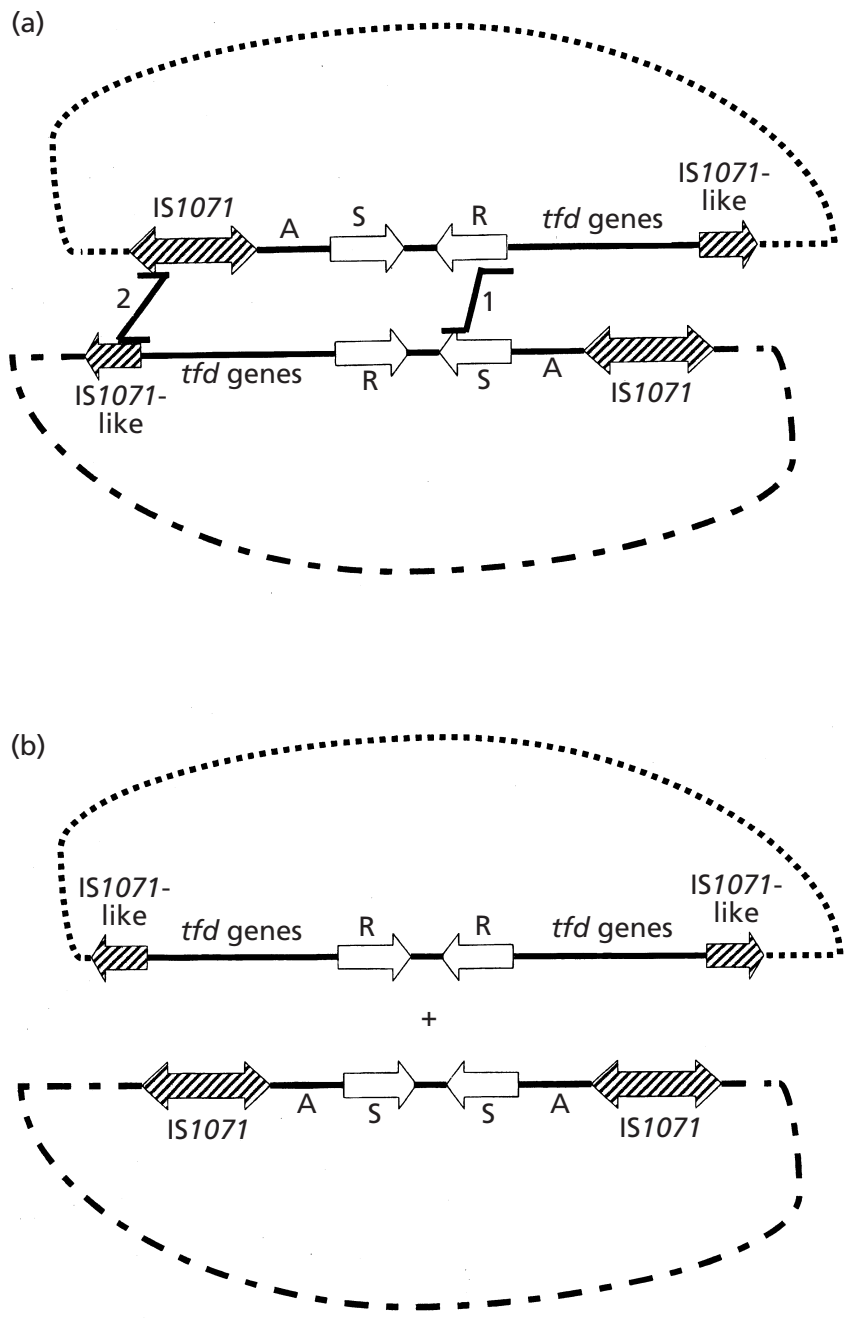

Fig. 3. Scheme for the intermolecular homologous recombination in pJP4 resulting in pJP4-F3. Two single crossovers take place (a) between the identical $t f d R / S$ sequences (1) and the homologous IS1071 elements (2), respectively, to give rise to two products (b). One corresponds to the rearranged plasmid characterized in this work. Note that no complete copy of the IS1071 is left in this plasmid, and that two copies of the $t f d_{1}$ and $t f d_{\|}$gene modules are present. The other recombination product should be lost upon transfer to liquid cultures with 3-chlorobenzoate.

cleavage pathway are documented for $c l c$ genes (Ravatn et al., 1998) and tcb genes (Klemba et al., 2000). Accumulation of 2-chloromuconate during growth of R. eutropha JMP134 on 3-CB has also been observed (Pieper et al., 1993), which can be explained by poor activity of chloromuconate cycloisomerases encoded by $t f d D_{\mathrm{I}}$ and $t f d D_{\mathrm{II}}$ genes (Pérez-Pantoja et al., 2000). If this is the rate-limiting step for growth on $3-\mathrm{CB}$, it can be partially overcome by a gene-dosage effect.

The simplest explanation for the rearrangement reported in pJP4-F3 is a double crossover, homologous recombination between two pJP4 molecules (Fig. 3). A single crossover occurs between the $t f d R$ sequence from 
one pJP4 molecule and the identical, but opposite, $t f d S$ sequence from the second pJP4 molecule. The second crossover takes place between the IS1071 sequence from one pJP4 molecule and the IS1071-like sequence from the other pJP4 molecule. This recombination gives rise to two rearranged plasmids (Fig. 3) : the first, pJP4-F3, is reported here, while the other one, lacking most of the tfd genes, is selected against during growth in the presence of 3-CB.

The available data suggest that the $t f d$ catabolic region is flanked by one complete copy of IS1071 and one end of this element, or an IS1071-like element (Figs 2 and 3). The IS1071 insertion sequence plays a role in several gene rearrangements (Tan, 1999; Wyndham et al., 1988), suggesting that this element may be involved in the pJP4 rearrangement reported here. Large deletions in pJP4 during conjugative transfer (Clément et al., 2000) or during transposon mutagenesis with Tn1771 (Don \& Pemberton, 1985) have been reported. In the latter case, deletion of an approximately $40 \mathrm{~kb}$ region encompassing $t f d$ catabolic genes was observed. That deletion corresponds roughly to the region framed by the IS1071 and the IS1071-like sequences reported here (Fig. 2a). As there are several examples of catabolic transposons containing IS1071 (Nakatsu et al., 1991; Peel \& Wyndham, 1999; Xia et al., 1998; Vedler et al., 2000), it is interesting to speculate that $\mathrm{pJP} 4$ originated from the insertion of an IS1071-based composite transposon (containing determinants for chloroaromatic metabolism) into an R751 IncP $\beta$-like element.

The search for ORFs in the sequences of $\mathrm{pJP} 4$ reported here revealed the presence of determinants for mercury resistance. Since DNA hybridization analyses of $\mathrm{pJP} 4$ with probes for Tn501 mer genes mapped these determinants to the EcoRI-F and EcoRI-D fragments, it has been proposed that the resistance to mercury in pJP4 is related to the presence of a Tn501 element (Burlage et al., 1990; Smith \& Thomas, 1987). Our results show that such ORFs are effectively present in this region of the pJP4 plasmid. The high level of homology suggests that these ORFs are actively involved in the resistance to mercury.

\section{ACKNOWLEDGEMENTS}

We thank Marlene Manzano and Rodrigo de la Iglesia for help with some experiments, Isabelle Hinner and Jean Armengaud for advice on sequencing, James Tiedje for providing the $t f d A$ DNA probe, and Rebecca Towers for critical reading of the manuscript. This work was supported by grants 8990004 from FONDECYT-Chile and IFS F/1886-3, and a collaborative grant from CONICYT (Chile) and BMBF-FZK (Karlsruhe, Germany). P.C. was supported by a doctoral FONDECYT grant (no. 2980046).

\section{REFERENCES}

Ausubel, F. M., Brent, R., Kingston, R. E., Moore, D. D., Seidman, J. G., Smith, J. A. \& Struhl, K. (editors) (1992). Short Protocols in Molecular Biology, 2nd edn. New York: Greene Publishing Associates.
Bradford, M. M. (1976). A rapid and sensitive method for the quantitation of microgram quantities of protein utilizing the principle of protein-dye binding. Anal Biochem 72, 248-254.

Brown, N. L., Ford, S. J., Pridmore, R. D. \& Fritzinger, D. C. (1983). Nucleotide sequence of a gene from the Pseudomonas transposon Tn501 encoding mercuric reductase. Biochemistry 22, 4089-4095.

Bullock, W. O., Fernandez, J. M. \& Short, J. M. (1987). XL1-Blue: a high efficiency plasmid transforming recA Escherichia coli strain with beta-galactosidase selection. BioTechniques 5, 376-379.

Burlage, R. S., Bemis, L. A., Layton, A. C., Sayler, G. S. \& Larimer, F. (1990). Comparative genetic organization of incompatibility group P degradative plasmids. J Bacteriol 172, 6818-6825.

Clément, P., Matus, V., Cárdenas, L. \& González, B. (1995). Degradation of trichlorophenols by Alcaligenes eutrophus JMP134. FEMS Microbiol Lett 127, 51-55.

Clément, P., Springael, D. \& González, B. (2000). Deletions of mob and tra pJP4 transfer functions after mating of Ralstonia eutropha JMP134 (pJP4) with Escherichia coli harboring F': : Tn10. Can J Microbiol 46, 485-489.

Don, R. H. \& Pemberton, J. (1981). Properties of six pesticide degradation plasmids isolated from Alcaligenes paradoxus and $A$. eutrophus. J Bacteriol 145, 681-686.

Don, R. H. \& Pemberton, J. (1985). Genetic and physical map of the 2,4-dichlorophenoxyacetic acid degradative plasmid pJP4. J Bacteriol 161, 466-468.

Fukumuri, F. \& Hausinger, R. P. (1993). Alcaligenes eutrophus JMP134 "2,4-dichlorophenoxyacetate monooxygenase" is an $\alpha$ ketoglutarate-dependent dioxygenase. J Bacteriol 175, 2083-2086.

Ghosal, D. \& You, I.-S. (1988). Gene duplication in haloaromatic degradative plasmids pJP4 and pJP2. Can J Microbiol 34, 709-715.

Ghosal, D., You, I.-S., Chatterjee, D. K. \& Chakrabarty, A. M. (1985). Genes specifying degradation of 3-chlorobenzoic acid in plasmids pAC27 and pJP4. Proc Natl Acad Sci USA 82, $1638-1642$.

Holben, W. E., Schroeter, B. M., Calabrese, V. G. M., Olsen, R. H., Kukor, J. K., Biederbeck, V. O., Smith, A. E. \& Tiedje, J. M. (1992). Gene probe analysis of soil microbial populations selected by amendment with 2,4-dichlorophenoxyacetic acid. Appl Environ Microbiol 58, 3941-3948.

Kado, C. I. \& Liu, S. T. (1981). Rapid procedure for detection and isolation of large and small plasmids. J Bacteriol 145, 1365-1373.

Klemba, M., Jakobs, B., Wittich, R.-M. \& Pieper, D. H. (2000). Chromosomal integration of $t c b$ chlorocatechol degradation pathway genes as a means of expanding the growth substrate range of bacteria to include haloaromatics. Appl Environ Microbiol 66, 3255-3261.

Kröckel, L. \& Focht, D. (1987). Construction of chlorobenzeneutilizing recombinants by progenitive manifestation of a rare event. Appl Environ Microbiol 53, 2470-2475.

Laemmli, C. M., Leveau, J. H., Zehnder, A. J. B. \& van der Meer, J. R. (2000). Characterization of a second $t f d$ gene cluster for chlorophenol and chlorocatechol metabolism on plasmid pJP4 in Ralstonia eutropha JMP134 (pJP4). J Bacteriol 182, 4165-4172.

Leveau, J. H. J. \& van der Meer, J. R. (1996). The $t f d R$ gene product can successfully take over the role of the insertion element-inactivated TfdT protein as a transcriptional activator of the $t f d C D E F$ gene cluster, which encodes chlorocatechol degradation in Ralstonia eutropha JMP134. J Bacteriol 178, 6824-6832.

Leveau, J. H. J., Konig, F., Fuchslin, H., Werlen, C. \& van der Meer, J. R. (1999). Dynamics of multigene expression during catabolic 
adaptation of Ralstonia eutropha JMP134 (pJP4) to the herbicide 2,4-dichlorophenoxyacetate. Mol Microbiol 33, 396-406.

Matrubutham, U. \& Harker, A. R. (1994). Analysis of duplicated gene sequences associated with $t f d \mathrm{R}$ and $t f d S$ in Alcaligenes eutrophus JMP134. J Bacteriol 176, 2348-2353.

Nakatsu, C., Ng, J., Singh, R., Straus, N. \& Wyndham, R. C. (1991). Chlorobenzoate catabolic transposon Tn5271 is a composite class I element with flanking class II insertion sequences. Proc Natl Acad Sci U S A 88, 8312-8316.

Peel, M. C. \& Wyndham, R. C. (1999). Selection of $c l c, c b a$, and $f c b$ chlorobenzoate-catabolic genotypes from groundwater and surface waters adjacent to the Hyde park, Niagara Falls, chemical landfill. Appl Environ Microbiol 65, 1627-1635.

Pérez-Pantoja, D., Guzmán, L., Manzano, M., Pieper, D. H. \& González, B. (2000). Role of $t f d \mathrm{C}_{\mathrm{I}} \mathrm{D}_{\mathrm{I}} \mathrm{E}_{\mathrm{I}} \mathrm{F}_{\mathrm{I}}$ and $t f d \mathrm{D}_{\mathrm{II}} \mathrm{C}_{\mathrm{II}} \mathrm{E}_{\mathrm{II}} \mathrm{F}_{\mathrm{II}}$ gene modules in catabolism of 3-chlorobenzoate by Ralstonia eutropha JMP134 (pJP4). Appl Environ Microbiol 66, 1602-1608.

Perkins, E. J., Gordon, M. P., Cáceres, O. \& Lurquin, P. F. (1990). Organization and sequence analysis of the 2,4-dichlorophenol hydroxylase and dichlorocatechol oxidative operons of plasmid pJP4. J Bacteriol 172, 2352-2359.

Pieper, D. H., Reineke, W., Engesser, K. H. \& Knackmuss, H.-J. (1988). Metabolism of 2,4-dichlorophenoxyacetic acid, 4-chloro2-methylphenoxyacetic acid and 2-methylphenoxyacetic acid by Alcaligenes eutrophus JMP134. Arch Microbiol 150, 95-102.

Pieper, D. H., Knackmuss, H.-J. \& Timmis, K. N. (1993). Accumulation of 2-chloromuconate during metabolism of 3-chlorobenzoate by Alcaligenes eutrophus JMP134. Appl Microbiol Biotechnol 39, 563-567.

Ravatn, R., Studer, S., Springael, D., Zehnder, A. J. B. \& van der Meer, J. R. (1998). Chromosomal integration, tandem amplifi- cation, and deamplification in Pseudomonas putida F1 of a 105-kilobase genetic element containing the chlorocatechol degradative genes from Pseudomonas sp. B13. J Bacteriol 180, 5505-5514.

Reniero, D., Mozzon, E., Galli, E. \& Barbieri, P. (1998). Two aberrant mercury resistance transposons in the Pseudomonas stutzeri plasmid pPB. Gene 208, 37-42.

Smith, C. A. \& Thomas, C. M. (1987). Comparison of the organization of the genomes of phenotypically diverse plasmids of incompatibility group $\mathrm{P}$ : members of the $\operatorname{IncP} \beta$ sub-group are closely related. Mol Gen Genet 206, 419-427.

Tan, H. M. (1999). Bacterial catabolic transposons. Appl Microbiol Biotechnol 51, 1-12.

Vedler, E., Koiv, V. \& Heinaru, A. (2000). Analysis of the 2,4-dichlorophenoxyacetic acid-degradative plasmid pEST4011 of Achromobacter xylosooxidans subsp. denitrificans strain EST4002. Gene 255, 281-288.

Wyndham, R. C., Singh, R. K. \& Straus, N. A. (1988). Catabolic instability, plasmid gene deletion and recombination in Alcaligenes sp. BR60. Arch Microbiol 150, 237-243.

Xia, X.-S., Aathithan, S., Oswiecimska, K., Smith, A. R. \& Bruce, J. (1998). A novel plasmid pIJB1 possessing a putative 2,4dichlorophenoxyacetate degradative transposon Tn5530 in Burkholderia cepacia strain 2a. Plasmid 39, 154-159.

You, I.-S. \& Ghosal, D. (1995). Genetic and molecular analysis of a regulatory region of the herbicide 2,4-dichlorophenoxyacetate catabolic plasmid pJP4. Mol Microbiol 16, 321-331.

Received 16 November 2000; revised 16 March 2001; accepted 3 April 2001. 